\title{
Transmedicalismo, corporalidades e sociedade
}

\author{
Transmedicalism, corporalities and society \\ Transmedicalismo, corporalidades y sociedad
}

Recebido: 04/08/2021 | Revisado: 13/08/2021 | Aceito: 19/08/2021 | Publicado: 22/08/2021

\author{
Melissa Salinas Ruiz \\ ORCID: https://orcid.org/0000-0002-7093-3215 \\ Universidade Estadual do Oeste do Paraná, Brasil \\ E-mail: m__salinas@hotmail.com
}

\begin{abstract}
Resumo
O termo transexual busca designar aqueles que não se identificam com o gênero que a sociedade lhes atribuiu ao nascer. Atualmente, os estudos de gênero têm mostrado que existem muitas formas de vivenciar a transexualidade, visto que é uma característica identitária. No entanto, o transmedicalismo é uma perspectiva que considera que só existe uma forma válida de viver a transexualidade. Partindo dessa noção, o objetivo deste artigo é discutir algumas manifestações contemporâneas do transmedicalismo, com ênfase na sociedade brasileira, bem como nas repercussões negativas dessa crença para os sujeitos trans. Para isso, utiliza o método de pesquisa bibliográfica, recorrendo a teóricos queer para embasar o entendimento sobre gênero e identidades trans. Começa explicando a origem da crença no verdadeiro transexual e demonstrando como ainda influencia a atenção à saúde das pessoas trans no Brasil. Em seguida, conceitua transmedicalismo, discutindo sua presença tanto nos protocolos de saúde quanto nos discursos da comunidade trans. Finalmente, apresenta pressupostos queer, utilizando-os para problematizar o pensamento transmedicalista.
\end{abstract}

Palavras-chave: Gênero; Sexo; Sexualidade; Transexualidade; Transmedicalismo.

\begin{abstract}
The term transgender refers to those that do not identify with the gender given to them by society. Currently, gender studies have shown that there are many ways of experiencing transsexuality, since it is an identity characteristic. Nevertheless, transmedicalism is the perspective that considers only one manner of experiencing transsexuality. Starting from this notion, the objective of this paper is to discuss some contemporary manifestations of transmedicalism, with emphasis on Brazilian society, as well as the negative repercussions of this belief for trans subjects. Therefore, uses bibliographic research as a method and recurs to queer theorist to base its understanding of gender and trans identities. This research begins by explaining the origin of the belief in the true transsexual and demonstrating how it still influences the health care of trans people in Brazil. Then explains the concept of transmedicalism and discuss it presence on health protocols and in the narratives of some trans people. Finally, presents queer presupposes and uses then to problematize transmedicalism.
\end{abstract}

Keywords: Genger; Sex; Sexuality; Transgender; Transmedicalism.

\section{Resumen}

El término transexual busca designar a aquellos que no se identifican con el género que la sociedad les atribuyó al nacer. Actualmente, los estudios de género demostraron que hay muchas maneras de vivir la transexualidad, puesto que es una característica identitaria. No obstante, el transmedicalismo es una perspectiva que considera que hay solo una manera valida de vivir la transexualidad. Partiendo de esa noción, el objetivo de este trabajo es discutir acerca de algunas manifestaciones contemporáneas del transmedicalismo, con énfasis en la sociedad brasileña, así como en las repercusiones negativas de esa creencia para los sujetos trans. Para tanto, utiliza el método de pesquisa bibliográfica, recuerriendo a teóricos queer para embasar la comprensión que posee de género e identidades trans. Inicia explicando el origen de la creencia en el verdadero transexual y demostrando como aun influencia la atención a salud de personas trans en Brasil. Luego, conceptua transmedicalismo, discutiendo su presencia tanto en los protocolos de salud cuanto en discursos de la comunidad trans. Finalmente, presente los presupuestos queer, utilizándolos para problematizar el pensamiento transmedicalista.

Palabras clave: Género; Sexo; Sexualidad; Transgénero; Transmedicalismo.

\section{Introdução}

Os estudos sobre transexualidade surgiram na seara das ciências biomédicas a fim de diagnosticar e tratar aqueles que apresentassem incongruência entre gênero e genital. Essa perspectiva patologizante foi mantida pelo discurso científico durante 
um longo período, repercutindo negativamente na maneira em que pessoas transexuais foram percebidas pela sociedade.

O surgimento dos estudos de gênero e queer - com estudos como os de Butler (2004) e Preciado (2014) defendendo o caráter socialmente construído de conceitos como gênero, sexo e sexualidade - aliados à atuação militante de sujeitos trans, possibilitaram perceber a transexualidade fora do âmbito da patologia. Passa a ser compreendida como identidade, sendo uma das múltiplas possibilidades de vivenciar o gênero. Nesse sentido, a edição mais recente da Classificação Internacional de Doenças - CID busca respaldar a despatologização, pois reclassifica a transexualidade, passando a enquadrá-la como condição pertinente à saúde sexual. Entretanto, não há um consenso acerca de quais benefícios de fato ocorrerão a partir dessa reclassificação (Coacci, 2019).

No Brasil, a possibilidade de retificar os documentos sem cirurgia de transgenitalização, resultado do julgamento da ação direita de inconstitucionalidade 4275 pelo STF (Almeida, 2018), também demonstra a flexibilização do uso de critérios biomédicos para definir a transexualidade. Conforme expõe Bento (2006), deve se falar em "transexualidades", posto que múltiplas e, consequentemente, incompatíveis com a crença em um modelo unívoco de transexual.

Porém, a ideia do "verdadeiro transexual" ainda não pode ser considerada como superada. Seja em razão do preconceito ou da falta de informação, o discurso que legitima algumas performances de gênero trans, a medida em que condena e invisibiliza outras, ainda é recorrente (Leite Júnior, 2008).

Essa perspectiva que compreende a transexualidade como um conjunto fixo de características é recorrente nos protocolos médicos de acesso a saúde, em âmbito nacional (Bento, 2006) e internacional (Zhang, 2019), sujeitando transindivíduos a performarem uma transexualidade clinicamente aceitável, sob risco de não obterem aval médico para realizar as modificações que almejam.

Entretanto, tal posicionamento não é adotado somente por pessoas cisgênero, isto é, que se identificam com o gênero que lhes foi designado ao nascer (Jesus, 2012). Paradoxalmente, existem pessoas transexuais que reproduzem em seus discursos a ideia de que há maneiras "corretas" de experienciar a transgeneridade. Denominados transmedicalistas, esses sujeitos refutam as trajetórias de quem vivencia a transexualidade de modos diversos.

Em face ao exposto, o objetivo deste artigo é problematizar as manifestações contemporâneas de transmedicalismo, com ênfase na sociedade brasileira, mas também mencionando suas expressões na comunidade trans online internacional. Dada a novidade da temática, este trabalho se ampara em pesquisas recentes como as de Miller (2016), Tadvick (2018) e Zhang (2019), assim como em teóricos queer conceituados, como Berenice Bento (2006), Judith Butler (2004) e Paul Preciado (2014).

Para alcançar o objetivo proposto, inicia-se expondo a origem da ideia do "verdadeiro transexual" na seara médica, relacionando-a com os requisitos do atual Processo Transexualizador (PrTr) do Sistema único de saúde (SUS). Logo, explicase o conceito de transmedicalismo, expondo como se encontra tanto em protocolos de acesso à saúde quanto no discurso de parcela da população transexual. Finalmente, apresentam-se as discussões queer, por meio das quais se critica o transmedicalismo.

\section{Metodologia}

O problema que impulsiona este trabalho é a indagação "o que é transmedicalismo e quais são suas manifestações contemporâneas?". Desse modo, busca responder a esse questionamento por meio dos seguintes objetivos específicos: a) conceituar transmedicalismo; b) relacionar o transmedicalismo à noção de verdadeiro transexual que ainda pauta a elaboração e interpretação de diversos diplomais legais, sobretudo da área da saúde; c) problematizar as manifestações contemporâneas do transmedicalismo, especialmente dentro da comunidade trans.

Para tanto, a presente proposta recorre ao método de pesquisa bibliográfica qualitativa, pois este promove a solução de 
questionamentos a partir da leitura crítica e análise de referenciais teóricos. Conforme afirma Boccato (2006), "esse tipo de pesquisa trará subsídios para o conhecimento sobre o que foi pesquisado, como e sob que enfoque e/ou perspectivas foi tratado o assunto apresentado na literatura científica".

Similarmente, Lima e Mioto (2007) enfatizam a relevância das pesquisas bibliográficas pois consideram que vão além da mera revisão bibliográfica, articulando teoria aos dados examinados e produzindo uma renovação crítica dos referenciais teóricos.

Desse modo, procurou-se pelo termo "transmedicalismo" no Banco de Teses e Dissertações da Coordenação de Aperfeiçoamento de Pessoal de Nível Superior (CAPES) no período de maio de 2021. Como não foi obtido nenhum resultado nessa busca, recorreu-se ao Google Acadêmico a fim de obter resultados para as palavras chave "transmedicalismo" e transmedicalism. A partir dos referenciais encontrados nessa busca, realizou-se sua leitura e análise com ênfase nos objetivos específicos expostos.

Complementarmente, a necessidade de discutir gênero e identidade trans faz com que esta investigação se baseie nas discussões queer de autores referência da área, a exemplo de Butler (2004) e Preciado (2014). Ainda, dada a ênfase que este trabalho dá às problemáticas brasileiras, torna-se necessário recorrer a importantes pesquisas nacionais, como as de Bento (2006), Rocon et. al (2016) e da Associação Nacional de Transexuais e Travestis (ANTRA, 2009), atualmente a única responsável pelo levantamento de dados acerca de violência contra pessoas transexuais no Brasil.

No entanto, devido à relevância das manifestações online de transmedicalismo oriundas da própria comunidade trans, este trabalho não se limita a um recorte geográfico brasileiro. A fim de poder analisar esse fenômeno, investigações como as de Miller (2016), Tadvick (2018) e Zhang (2019) se fazem fundamentais, especialmente pela novidade da temática, a qual gera uma escassez de referencial teórico.

Por considerar que a origem do transmedicalismo se vincula às primeiras pesquisas sobre transexualidade na área das ciências psi, autores como Benjamin (1999) e Stoller (1982) são mencionados, visto que seus estudos ainda exercem influência na compreensão contemporânea que se tem da transexualidade, a despeito da OMS tê-la reclassificado em sua nova proposta da Classificação Internacional de Doenças (Rodrigues \& Mesquita, 2019).

Finalmente, enfatiza-se que as problematizações realizadas nesta investigação buscam dar a conhecer algumas das consequências contemporâneas da percepção transmedicalista, não pretendendo fornecer um rol exaustivo destas, mas incentivar o debate crítico acerca das implicações da crença em um estereótipo de transexualidade.

\section{Primeiras Discussões Sobre Transexualidade}

O termo transexual surgiu a partir dos estudos de Magnus Hiershcfeld (1868-1935), numa tentativa de descriminalizar a performance desses indivíduos. Ao considerá-la patologia, esse teórico se posicionava contrariamente à dura repressão policial e judicial que esses sujeitos sofriam na Alemanha. Por esse motivo, Stryker (2017) considera a contribuição de Hirschfeld ambígua, posto que, embora tenha constituído um avanço à época, compelia transindivíduos a se classificarem como doentes para poder aceder a tratamentos médicos e intervenções cirúrgicas.

Dando continuidade a esses estudos, autores como Robert Stoller (1982) e Harry Benjamin (1999) compreenderam a transexualidade de diferentes maneiras. Para Benjamin, médico endocrinologista autor do livro The transsexual phenomenon (1966), a transexualidade possuía origem biológica, sendo um "desvio" da "heterossexualidade natural" (Benjamin, 1999). Consequentemente, "a única chance de cura seria a realização da cirurgia de redesignação sexual, colocando assim em conformidade os demais sexos ajustados ao psicológico" (Almeida, 2018, p.33).

Sobre a influência de Benjamin na seleção das características que constituem o "verdadeiro transexual", expõe Leite Júnior: 
São elas, a insistência em se considerar uma 'mulher em corpo de homem' (ou uma 'alma feminina em corpo masculino') o repúdio, o ódio aos próprios genitais e a urgente necessidade de alterar seu corpo, adequando-o ao sexo que considera ser correto; e, finalmente, uma profunda angústia ou infelicidade quanto à sua condição (Leite Júnior, 2008, p. 142)

De modo diverso, Stoller (1982) defendia que a transexualidade decorria das relações sociais, especificamente do tipo de vínculo que a pessoa transexual estabelecia com sua mãe na infância. Nota-se que, apesar de apresentarem diferentes análises a respeito da transgeneridade, ambos autores se assemelham ao definir "critérios para se diagnosticar o verdadeiro transexual" (Bento, 2006, p. 133)

Em virtude desses estudos e das decorrentes pesquisas influenciadas por eles, em 1980 a transexualidade é incluída na Classificação Internacional de Doenças - CID, o qual foi comemorado pelos profissionais de saúde da época, visto que esse "reconhecimento" auxiliaria o diagnóstico e cura (Stryker, 2017).

No Brasil, o PrTr do SUS possui forte inspiração na noção do "verdadeiro transexual" e é criticado pela sua rigidez por autores como Almeida (2018), Bento (2006), Oliveira (2013) e Rego (2015). O PrTr surge em 2008, por meio da Portaria 1707 "passando a permitir o faturamento dos procedimentos transgenitalizadores, incorporando-os na tabela de procedimentos do SUS (Rocon et. al., 2019, p.2). Entretanto, o início da oferta de serviços de saúde específicos para pessoas trans data de 1997, a partir da Resolução 1482 do Conselho Federal de Medicina (CFM). Segundo Rocon et al. (2016, p.262), essa resolução parte de uma perspectiva patologizante, pois "o CFM partiu da medicalização das identidades de gênero trans, tornando a patologização requisito ao acesso para normatizar os procedimentos transgenitalizadores".

A Resolução 2265/2019, normativa mais recente do CFM determina a idade mínima de 16 anos para o acompanhamento clínico e hormonioterapia e de 18 anos para a realização de cirurgia. Em respeito à CID-11, adota a terminologia “incongruência de gênero", frisando a importância do respeito à identidade de gênero, e estabelece o acompanhamento psiquiátrico por período não inferior a um ano (Brasil, 2019).

Acerca desse acompanhamento, considera-se que é necessário ir além das mudanças normativas a fim de garantir a efetividade desses posicionamentos em âmbito ambulatorial. Segundo Rocon et. al (2016), o acompanhamento terapêutico de pessoas trans requeria destas que rejeitassem seu genital e todas as características de seu sexo primário e secundário enquanto durasse o tratamento. A semelhança das noções benjaminianas, pautava-se em um rígido binarismo de gênero, uma vez que a noção do que é feminino ou masculino decorre da normatização dessa binariedade (Butler, 2004). Desse modo, Coacci (2018) enfatiza que mudanças voltadas à despatologização nem sempre conseguem um tratamento mais humanizado na prática.

Ainda, considera-se que a maneira como a Resolução 2265/2019 define travestis, homens transexuais e mulheres transexuais é limitante e estritamente vinculada à relação que o indivíduo possui com o genital, assim ignorando os demais aspectos que se relacionam à adoção de determinada identidade em detrimento de outra. Perspectivas como a de Moira, por exemplo, quem defende o uso do termo travesti por considerar a palavra transexual demasiado higienizada, ficam invisibilizadas, restritas a aspectos genitalizantes. Similarmente, identidades como a transvestigênere, cunhada e defendida por Indianare Siqueira, não são contempladas (Lustosa, 2016).

\section{Transmedicalismo}

Zhang (2019) define transmedicalismo como a percepção de que a transexualidade é uma condição essencialmente médica. No mesmo sentido, Feraday (2016) dispõe que transmedicalistas defendem uma vivência trans pautada na disforia, ou seja, associada a ideia de pertencer a um corpo errado, sendo necessária a transição médica completa.

Os critérios rígidos de diagnóstico pelos quais pessoas trans são submetidas para acessar protocolos médicos de modificação corporal seguem essa perspectiva transmedicalista. motivo pelo qual são criticados por entidades de militância 
trans e teóricos queer (Zhang, 2019). Nesse âmbito, poderia se assumir que o transmedicalismo é defendido exclusivamente por cisgêneros. Entretanto, também é possível observar discursos transmedicalistas dentro da comunidade trans. Serano (2007) aponta que, embora o transmedicalismo tenha surgido no âmbito do sistema de saúde, seu discurso expandiu-se para além das ciências psis, manifestando-se inclusive dentro da própria comunidade trans.

Ao observar as dinâmicas de pessoas não-cis e não-hétero na rede social Tumblr, Feraday (2016, p.39) deparou-se com o termo "truscum", denominação pejorativa utilizada para designar pessoas trans que marginalizam, consciente ou inconscientemente, transindivíduos que se distanciam da imagem do "verdadeiro transexual". Os "truscum", assim, seriam pessoas transexuais que reforçam a ideia transmedicalista de que há uma maneira correta de ser transexual (Lima, 2020, p.22).

Cannerstad (2019, p.33) exemplifica expondo o dilema da transmulher Tali, administradora de Kadath, comunidade online de apoio à população trans. Segundo Tali, é complicado lidar com a presença de transmedicalistas nos grupos pois constituem um número relevante de membros, o que a impede simplesmente de bani-los. $\mathrm{O}$ transmedicalismo dentro desses grupos de apoio leva ao surgimento de hierarquias pautadas não no bem-estar do grupo, mas no cumprimento de etapas que passam a ser consideradas necessárias para poder se considerar verdadeiramente trans.

Complementarmente, Miller (2016, p.20) observa que, a fim de desmerecer sujeitos trans que não consideram urgente a realização de cirurgias em suas transições de gênero, sujeitos transexuais transmedicalistas os chamam de "transtrenders" ou guerreiros da justiça social, alegando que se afirmariam trans apenas para obter visibilidade como militantes sociais. Feraday (2016) relaciona os discursos transmedicalistas de pessoas transexuais com a tentativa de ser aceitos por indivíduos com privilégios hétero e cisgênero, assim tentando se afastar de uma parcela da comunidade trans que seria mais marginalizada pelo sistema cisgênero.

A respeito da relação entre pessoas transexuais transmedicalistas e militância, Fisher (2019) observa em sua pesquisa etnográfica que o discurso predominante entre eles distancia a existência transgênero da política, considerando a transexualidade como uma circunstância de vida ao acaso. De modo diverso, indivíduos trans contrários ao transmedicalismo se demonstraram muito mais engajados politicamente.

Acerca do vínculo entre transidentidade e militância, Lanz (2018) destaca que não deve ser esperado que transindivíduos vivenciem seu gênero de maneira política, propositalmente transgressora. Segundo a autora, quanto maior o distanciamento das normas sociais de gênero, mais sujeito à segregação e violência se encontra o indivíduo. Portanto, os aspectos constatados por Fisher (2019) devem ser compreendidos com ressalvas, uma vez que a ausência de atuação militante não constitui, necessariamente, indicativo de que haja o repúdio pelas demais maneiras de vivenciar a transgeneridade.

Entretanto, os resultados de Fisher (2019) vão ao encontro das considerações de Rego (2015) a respeito da influência da atuação militante para transindivíduos. Em sua pesquisa, Rego (2015) identificou que o engajamento militante consiste em um fator relevante na percepção que os indivíduos possuem de si e de suas vivências de gênero. Devido a essa influência, o autor pondera que é possível pensar no envolvimento militante como um marcador social de diferença. Em suma, os aspectos constatados por Fisher (2019) podem ser relacionados às proposições de Rego (2015), uma vez que a participação política de pessoas transexuais pôde ter contribuído a uma leitura menos binária da experiência trans.

Tadvick (2018) ressalta a relação entre transmedicalismo e binarismo de gênero, posto que essa visão da transexualidade se assenta na noção que considera necessária a correspondência entre genitália e identidade de gênero. Desse modo, ao associarem a transexualidade ao necessário desejo de uma transição médica completa, indivíduos transexuais auxiliariam o sistema cisgênero - ou cistema, como denomina Vergueiro (2015, p.76) - a perpetuar os mecanismos de opressão de gênero.

Ao investigar como são as interações na rede social Twitter entre grupos feministas e grupos trans na Espanha pesquisa que realizou do período de abril de 2019 a abril de 2020 - Luna (2020, p.57) encontra o uso do termo truscum como 
crítica a pessoas transexuais que negam identidades não-binárias. Além da expressão insultosa, a autora menciona tweets abertamente hostis, nos quais transmedicalistas são xingados e excluídos dos grupos online por meio de ferramentas como Blockchain, recurso do Twitter que permite bloquear o acesso do contato a uma rede de conteúdo.

Feraday (2016) também relaciona as práticas online transmedicalistas de transexuais à negação de neoidentidades, como as não binárias. No mesmo sentido, Zhang (2019) afirma que neoidentidades levam ao rompimento do paradigma transmedicalista de que a disforia é um elemento constitutivo da transgeneridade.

Acerca das vivências trans contemporâneas - entre as quais se compreende as neoidentidades - Kando (2016) afirma que cada vez mais transindivíduos se distanciam da busca ininterrupta pela passabilidade, ou seja, pela aparência que fará com que sejam lidos como cisgênero. Essa transformação ocorre em razão da maior visibilidade e importância dos movimentos políticos de lésbicas, gays, bissexuais, transexuais, queer e intersexo (LGBTQI), os quais permitem que sujeitos trans se apropriem de suas narrativas, abandonando a vitimização que o discurso médico lhes atribuiu durante um longo período. Esse processo, no entanto, depende de muitos fatores, sendo um deles o grau de avanço dos direitos LGBTQI do local onde se encontram (Kando, 2016).

A partir disso, pode ser suposto que há relação entre trans transmedicalistas e o fato de residir em comunidades onde o cistema ainda predomina, oprimindo as identidades cis divergentes. Considera-se que essa interpretação vai ao encontro de Feraday (2016) quando relaciona o transmedicalismo em pessoas transexuais ao desejo de serem aceitos por sujeitos cisgênero.

Contudo, independente das hipóteses que possam ser tecidas para tentar compreender a defesa do transmedicalismo por algumas pessoas da comunidade trans, deve ser destacado que a defesa do "verdadeiro transexual" se origina no cistema heteronormativo. Assim, mesmo quando reproduzem esse discurso, pessoas trans não são a causa do problema, mas reflexos da sociedade centrada no binarismo de gênero e na cisgeneridade.

Além de determinar a existência transexual pela presença de disforia, o transmedicalismo traz consequências jurídicas. Assim aponta Zhang (2019) ao analisar demandas judicias de pessoas trans encarceradas nos EUA. Segundo o autor, as demandas por necessidades médicas de indivíduos transexuais encarcerados são analisadas pelas cortes em busca de atos como automutilação, autocastração, entre outros, a fim de serem julgadas procedentes. Ainda, o autor destaca que aumenta a probabilidade de obter o provimento judicial quanto menos agência o indivíduo trans demonstre, o qual evidencia a crença transmedicalista de que o sofrimento e inadequação - a disforia - são inerentes à vivência trans.

Entretanto, pesquisas como as de Butler (2004), Bento (2006) e Kulick (2008) demonstram que a experiência trans é muito mais complexa do que apontam os discursos transmedicalistas. Portanto, no seguinte tópico se expõem as perspectivas teóricas que possibilitaram compreender a transexualidade como vivência identitária, consequentemente repudiando o transmedicalismo.

\section{Transexualidades Múltiplas: Críticas queer ao Transmedicalismo}

A respeito da relação entre gênero e orientação sexual, Butler (2004) afirma que os binômios homem/mulher e hétero/homossexual não são naturais, mas produzidos e reforçados através do discurso das instâncias de poder regulador. Consequentemente, os dispositivos reguladores do gênero são os responsáveis pela naturalização do hétero em detrimento do homo e do cisgênero em oposição ao transgênero, não existindo uma ordem natural cisgênera e heterossexual. Assim, compreende-se o trans como uma das muitas possibilidades de vivenciar o gênero. Denominada queer, essa perspectiva teórica encontra cada vez mais respaldo dentro da academia, uma vez que reflete o posicionamento de importantes militâncias trans, em âmbito nacional e internacional (ANTRA, 2019). No Brasil, são importantes nomes dessa militância as pesquisadoras doutoras transfeministas Jaqueline Gomes de Jesus, Viviane Vergueiro e Letícia Lanz, assim como as vereadoras Erika Hilton e Duda Salabert. 
Durante o período em que realizava sua pesquisa doutoral, Bento (2006) observou que os indivíduos que almejavam acessar o $\operatorname{PrTr}$ se submetiam a uma espécie de "assepsia", pois consideravam que seu sucesso em obter a cirurgia de transgenitalização dependia de uma performance que estivesse de acordo às expectativas dos profissionais da saúde responsáveis por atendê-los.

A partir disso, a autora notou a diversidade dos relatos dos pacientes que se submetiam ao PrTr. Enquanto alguns desejavam modificar seus genitais a qualquer custo, outros se interessavam mais pelo reconhecimento social que obteriam após a cirurgia. Entretanto, o que não se alterava era a certeza de pertencer a um gênero distinto do que lhes fora atribuído ao nascer (Bento, 2006).

No mesmo sentido, ao acompanhar a transição de homens trans, Rego (2015) observa que o discurso médico não contempla todas as maneiras em que eles transicionam:

Os interlocutores deste trabalho, aqueles com os quais mantive contato, seja por meio direto etnográfico, seja apenas por entrevistas, apresentaram-se em um fazer-se homem trans distante da oficialidade dos protocolos médicopsicológicos - o que não é o mesmo que dizer que estejam totalmente para além desses protocolos (Rego, 2015, p. 95)

A hormonização, de acordo ao $\operatorname{PrTr}$, deve começar apenas aos 16 anos. No entanto, estudos como os de Benedetti (2005) e Cabral (2012) identificam que pessoas trans, não raro, hormonizam-se antes disso, motivadas pelo desejo de evitar o desenvolvimento das características sexuais secundárias.

Segundo Pelúcio (2005), a hormonização é item fundamental no processo de "ser travesti”. Para a autora, esse processo jamais se encerra, sendo os hormônios uma das intervenções estéticas mais valorizadas. Desse modo, quanto mais cedo as travestis iniciarem em seu uso, mais bonitas e exitosas são consideradas.

É possível pensar os hormônios como uma das tecnologias sexopolíticas às quais recorrem os dissidentes sexuais e de gênero (Preciado, 2011, p.16). A respeito dessas técnicas de modificação corporal, o filósofo afirma que "o gênero é, antes de tudo, prostético, ou seja, não se dá senão na materialidade dos corpos" (Preciado, 2014, p.29). Com isso, o teórico busca afirmar a liberdade do corpo, que se estabelece como receptáculo material que tudo pode, livre das amarras sociais que determinam a anatomia de um corpo feminino ou masculino (Haddock-Lobo, 2018). Ainda, complementa que "os órgãos que reconhecemos como naturalmente sexuais já são o produto de uma tecnologia sofisticada que prescreve o contexto em que os órgãos adquirem sua significação (relações sexuais) e de que se utilizam com propriedade" (2014, p. 31). Desse modo, o autor afirma o caráter político da arquitetura do corpo, posto que constantemente sujeito a práticas de modificação corporal. Adicionalmente, o autor defende que a relação sexual heterossexual é uma das muitas possibilidades de leitura sexual do corpo.

Conforme Stryker (2017), o prefixo "trans" demonstra que esses sujeitos atravessam o cisgênero, travessia que, afirma a autora, é distinta para cada um deles. Contrariando a percepção do discurso médico patologizante, a transexualidade não se limita a um grupo estático de características, compreendendo todos os indivíduos que desejam materializar em seus corpos, em maior ou menor grau, um gênero distinto do que lhes foi socialmente atribuído ao nascer.

A partir do exposto, percebe-se que a definição de transgênero contida no PrTr é limitante, inspirada por estudos médicos de outrora, os quais associavam a transexualidade a uma disposição anímica depressiva (Bento, 2006) e ao total repúdio pelo próprio genital. Nesse âmbito, discursos trans como o de Preciado (2014) buscam questionar a pretensa naturalidade das performances de gênero e sexuais, visto que não existe um corpo humano anterior à percepção socialmente construída que se faz dele. Por conseguinte, desconstrói-se a ideia de que o corpo cis é o parâmetro de normalidade, problematiza-se a compreensão acerca do que seria masculino ou feminino, além de se incentivar a pensar o gênero para além da perspectiva binária. 
O julgamento da ADI 4275 pelo STF indica avanços nesse sentido, uma vez que acaba com a obrigatoriedade de cirurgia de redesignação sexual para ser realizada a alteração do nome e gênero junto ao registro civil (Almeida, 2018). A Classificação Internacional de Doenças - CID 11, ao reclassificar a transexualidade, busca respaldar a despatologização, sendo esse tipo de medida um passo importante para oferecer um tratamento em saúde mais humanizado à população trans (Borba, 2014). No entanto, cabe mencionar que não deixam de ter validade críticas como as de Almeida e Murta (2013) que ressaltam a impossibilidade de avanços significativos se a despatologização não vier acompanhada de capacitação e demais estratégias que melhorem o acesso de pessoas trans à saúde.

Interpretam-se os embates expostos como vestígios de uma estrutura cisnormativa que, ainda hoje, deslegitima sujeitos transgêneros que não se adequem aos estereótipos de gênero vigentes. Nas palavras da autora transfeminista Jaqueline Gomes de Jesus:

Para muitos de nós, pessoas trans, a Medicina é vista como uma ciência maligna e essa premissa tem lá suas razões de ser, considerando o histórico de violências simbólicas e físicas perpetrado contra os corpos da população trans, pelo poder biomédico, o qual só é superado pelo poder policial (2016, p.199).

Miller (2017) relaciona o transmedicalismo à transnormatividade, pela qual a experiência trans correta, normativa, seria aquela mais próxima às hierarquias sociais que estabelecem o padrão como branco, de classe média, sem deficiências, heterossexual e em plena adequação aos padrões de gênero masculinos ou femininos. Seguindo essa noção de normatividade, Bonassi (2017, p.75) questiona se a disforia não seria produto "de uma normalização cisnormativa que constantemente busca o verdadeiro sexo?". A partir dessa constatação, percebe-se o estreito vínculo entre uma sociedade cisnormativa e heterocentrada e a negação das "multidões queer" defendidas por Preciado (2011, p.14), gerando assim uma aceitação estratégica da identidade trans, estritamente pautada na manutenção das noções binárias dessa sociedade.

$\mathrm{O}$ transmedicalismo cria hierarquias dentro da população trans, fazendo com que modificações corporais sejam encaradas como "passaportes", verdadeiros meios de acesso à reinvindicação da identidade transexual (Cannerstad, 2019, p.31). Nesse sentido, considera-se importante analisar as distintas maneiras em que o transmedicalismo se manifesta, bem como enfatizar sua relação com o discurso biomédico, pois através da constante atualização das práticas em saúde poderá se reverter o cenário atual. No Brasil, assegurar o atendimento de saúde humanizado e flexibilizar os protocolos de acesso à saúde são algumas medidas que permitiriam aos transindivíduos vivenciar seus gêneros de maneira mais livre e menos pautada em normatizações de gênero binárias.

Os grupos de apoio online também podem ser importantes locais de enfrentamento à ideologia transmedicalista. Segundo Caddernath (2019), o compartilhamento de conteúdo erótico e sensual na comunidade Kaddath auxilia a minimizar a influência dos discursos transmedicalistas, posto que evidencia a diversidade de corpos. Ainda, esses grupos dão a conhecer quão individual é o processo de transição para cada sujeito, o que se faz particularmente relevante dado o modo como grupos de apoio offline e online acabam complementando o cuidado recebido pela comunidade trans pelos sistemas de atenção à saúde.

Em suma, acredita-se que deve existir uma atuação conjunta da sociedade no sentido de cobrar atendimento médico humanizado e de qualidade para as pessoas trans, respeitando a individualidade destas. Acredita-se que iniciativas nesse sentido contribuiriam com a diminuição de dicursos transmedicalistas posto que os dispositivos que reforçam a ideia de uma verdadeira transexualidade acabariam perdendo sua força e seu potencial normatizador. 


\section{Considerações Finais}

Ao longo desta proposta se discutiu a respeito do transmedicalismo, perspectiva percebida como consequência da crença no verdadeiro transexual. Desse modo, expôs-se a origem do termo transexualidade, a maneira como esta foi associada ao patológico e o decorrente surgimento de protocolos médicos de atendimento à população trans pautados em rígidos critérios diagnósticos.

Partiu-se da noção de Serano (2007) acerca do surgimento do transmedicalismo na esfera da saúde para discutir como este influencia os protocolos de acesso à saúde no Brasil, com ênfase na relação entre o PrTr do SUS e a ideia de uma maneira correta de ser transgênero. Também foi problematizada a despatologização proposta pelo CID-11, ressaltando a necessidade de articular práticas efetivamente humanizadas aos discursos normativos sobre despatologização.

A fim de contestar a crença transmedicalista, apresentamos autores queer que, por meio de sua defesa de uma vivência de gênero livre do rigor normativo, compreendem a percepção do que é masculino e feminino como fruto de normas de gênero criadas e reproduzidas pela sociedade. Portanto, a ideia de que existe um verdadeiro transexual se ampara muito mais em uma tentativa de manter o binarismo de gênero do em uma real compreensão das experiências trans.

Adicionalmente, demonstrou-se que o transmedicalismo não se faz presente somente entre pessoas cisgênero, existindo discursos transmedicalistas dentro da própria comunidade trans, grupo que é denominado pejorativamente de "truscum" (Feraday, 2016). Forneceram-se alguns exemplos de como o transmedicalismo se manifesta online - como o surgimento de hierarquias dentro da comunidades trans pautadas por noções estereotipadas de transexualidade - e, a partir deles, foram tecidas considerações a respeito da relação entre transmedicalismo, transexualidade e militância.

Subsequentemente, relacionaram-se as ideias transmedicalistas ao sistema social heterocentrado, assim como à falta de envolvimento com movimentos de militância pelos direitos de transindividuos. Contudo, enfatizou-se que essa abordagem não se propõe a estigmatizar pessoas trans partidárias da percepção transmedicalista, sobretudo considerando a ênfase de Lanz (2018) acerca da reprovabilidade em exigir posturas revolucionárias de transindivíduos. As relações propostas apenas buscam estabelecer conexões que expandam os modos como se compreendem as subjetividades trans, assim como enfatizar a importância da militância na construção dessas subjetividades.

Finalmente, frisou-se a influências dos procedimentos do Processo Transexualizador do SUS na construção de subjetividades que embasam o transmedicalismo, uma vez que o PrTr não contempla algumas identidades cis divergentes, a exemplo de pessoas trans não binárias. Ainda, enfatizou-se como o transmedicalismo pode influenciar as práticas de saúde pelas quais a despatologização normativa não é reforçada por uma práxis de atuação despatologizante - e o acesso jurisdicional - conforme pontuado por Zhang (2019) ao expor a visão transmedicalista por trás das decisões judiciais no momento de aprovar requerimentos de saúde de pessoas trans em situação prisional nos EUA.

\section{Referências}

Almeida, A. S. (2018) Vidas em espera: uma etnografia sobre a experiência do tempo no processo transexualizador. (Dissertação de mestrado). Mestrado em Antropologia Social) - Universidade Federal de Goiás, Goiânia, Brasil.

Almeida, G. \& Murta, D. (2013). Reflexões sobre a possibilidade da despatologização da transexualidade e a necessidade da assistência integral à saúde de transexuais no Brasil. Revista Latinoamericana Sexualidad, Salud y Sociedad, (14), 380-407. https://doi.org/10.1590/S1984-64872013000200017

ANTRA. (2019). Dossiê assassinatos e violência contra travestis e transexuais no Brasil em 2018. https://antrabrasil.org/mapadosassassinatos/.

Benedetti, M. (2005). Toda feita: o corpo e o gênero das travestis. Garamond.

Benjamin, H. (1999) The Transsexual Phenomenon. Symposium Publishing: Düsseldorf.

Bento, B. (2006). A reinvenção do corpo: sexualidade e gênero na experiência transexual. Garamond. 
Boccato, V. R. C. (2006). Metodologia da pesquisa bibliográfica na área odontológica e o artigo científico como forma de comunicação. Revista de Odontologia da Universidade Cidade de São Paulo, 18(3), 265-274. http://www.cidadesp.edu.br/old/publicacoes/revista_ odontologia/revista_odontologia_3/pdf_completo.pdf

Bonassi, B. C. (2017). Cisnorma: acordos societários sobre o sexo binário e cisgênero. (Dissertação de mestrado). Centro de Filosofia e Ciências Humanas, Universidade Federal de Santa Catarina, Florianópolis, Brasil. https://www.google.com.br/url?sa=t\&rct=j\&q=\&esrc=s\&source=web\&cd=\&cad= rja\&uact=8\&ved=2ahUKEwjCibTY7bjyAhWQIbkGHemEClgQFnoECAYQAw\&url=https\%3A\%2F\%2Frepositorio.ufsc.br\%2Fhandle\%2F123456789\%2F1 82706\&usg=AOvVaw2TyHFb6r5fuPHiw9TW-Tju

Borba, R. (2014). Sobre os obstáculos discursivos para a atenção integral e humanizada à saúde de pessoas transexuais. Revista Latinoamericana Sexualidad, Salud y Sociedad, (17), 66-97. https://doi.org/10.1590/1984-6487.sess.2014.17.06.a

BRASIL. Conselho Federal de Medicina. Resolução n. 2265, de 20 de setembro de 2019. Dispõe sobre o cuidado específico à pessoa com incongruência de gênero ou transgênero e revoga a Resolução CFM nº 1.955/2010. Diário Oficial da União. 9 Jan 2020.

Butler, J. (2004). Undoing gender. Routledge.

Cabral, J.V. (2012). Geografía travesti: cuerpos, sexualidade y migraciones de travestis brasileñas (Rio de Janeiro - Barcelona). (Tesis de doctorado). Departamento de Antropologia Cultural e Historia de América y África, Universidad de Barcelona, Barcelona, España. https://www.tdx.cat/handle/10803/95889

Cannerstad, K. (2019). Women without borders - how trans women find themselves online: a qualitative study on trans women in online support communities. (Bachelor's degree). Faculty of Arts and Social Sciences, Karlstad University, Karlstad, Sweden. http://www.divaportal.org/smash/get/diva2:1342357/FULLTEXT01.pdf

Coacci, T. (2019). Como funciona a despatologização na prática? Rev. Estud. Fem. 27 (2). 10.1590/1806-9584-2019v27n258001

Feraday, C. (2016). For lack of a better word: neo-identities in non-cisgender, non-straght communities on TUMBLR. (Masters dissertation). Program of communication and culture, University of Toronto, Toronto, Canada. https://digital.library.ryerson.ca/islandora/object/RULA\%3A5628/datastream/OBJ/view

Fisher, J. (2019). Transgender Digital Embodiments: Questions of the Transgender Body in the 21st Century. (Masters dissertation). Interdisciplinary Studies Department, Kennesaw States University, Georgia, States America. https://digitalcommons.kennesaw.edu/cgi/viewcontent.cgi?article=1026\&context=mast_etd

Grant, C. (2015). Direito, bioética e transexualidade: um estudo sobre os limites e as possibilidades de ampliação da tutela jurídica das experiências trans*. (Dissertação de mestrado). Programa de Pós-Graduação em Direito, Universidade Federal da Bahia, Salvador, Bahia, Brasil. https://repositorio.ufba.br/ri/bitstream/ri/17741/1/DISSERTA\%C3\%87\%C3\%83O\%20-\%20TEXTO\%20COMPLETO\%20COM\%20FICHA\%20-

\%20CAROLINA\%20GRANT\%20-\%2002.03.2015.pdf

Haddock-Lobo, R. (2018). Que "corpo" é esse de Preciado? (Ou que corpos depreciados são esses?). Concinnitas, 1 (32), 85-122. https://www.epublicacoes.uerj.br/index.php/concinnitas/article/download/36509/26365

Jesus, J. G. de. (2012). Orientações sobre identidade de gênero: conceitos e termos. Brasília. https://files.cercomp.ufg.br/weby/up/16/o/ORIENTA\% C3\%87\%C3\%95ES_SOBRE_IDENTIDADE_DE_G\%C3\%8ANERO_CONCEITOS_E_TERMOS_-

_2\%C2\%AA_Edi\%C3\%A7\%C3\%A3o.pdf?1355331649

Jesus, J. G. de. (2016). Medicina: uma ciência maligna? Debate psicopolítico sobre estereótipos e fatos. Periódicus, 1(5), 195-204. https://revistas.ufba.br/index.php/revistaperiodicus/article/download/17187/11342

Kando, T. (2016). The transsexual phenomenon in a changing culture. http://tomkando.com/professional_publications.shtml

Lanz, L. (2018). Por que tenho medo de lhe dizer quem sou? In: Ribeiro, P. R. C. et al. (Org). Corpo, gênero e sexualidade: resistência e ocupa(ações) nos espaços de educação. (49-69). Ed. Da FURG.

Leite Júnior, J. (2008). Nossos corpos também mudam: sexo, gênero e a invenção das categorias "travesti” e "transexual” no discurso científico. (Tese de doutorado). P rograma de Estudos Pós-Graduados em Ciências Sociais, Pontíficia Universidade Católica de São Paulo, São Paulo, Brasil. Recuperado de https://tede2.pucsp.br/bitstream/handle/3992/1/Jorge\%20Leite\%20Junior.pdf

Lima, T. C. S. de., \& Mioto, R. C. T. Procedimentos metodológicos na construção do conhecimento científico: a pesquisa bibliográfica. Revista Kátal, 10(spe), 37-45. https://doi.org/10.1590/S1414-49802007000300004

Luna, A. G. (2020). "Lo trans" cooptación de identidades y sus consecuencias en el discurso de la web 2.0: Twitter. (Disertación de Maestria). Facultad de Filosofía y Letras, Ciudadanía, Universidad de Cádiz, Cádiz, España. https://rodin.uca.es/xmlui/bitstream/handle/10498/23694/TFM $\% 20 \mathrm{Abel} \% 20 \mathrm{Gonz} \% \mathrm{C} 3 \%$ A1lez\%20Luna.pdf?sequence=1\&isAllowed=y

Lustosa, T. (2016). Manifesto traveco-terrorista. Revista Concinnitas, 1 (18), 385-409. https://www.google.com.br/url?sa=t\&rct=j\&q=\&esrc=s\&source =web\&cd=\&ved=2ahUKEwiw67bmorjyAhU6KLkGHWRCD-EQFnoECAQQAQ\&url=https\%3A\%2F\%2Fwww.e-publicacoes.uerj.br\%2Findex .php\%2F conc innitas\%2Farticle\%2Fview\%2F25929\%2F18560\&usg=AOvVaw2cv2E1ZqyyHLy_8r4MhvTK

Miller, J. F. (2016). I wanna know where the rule book is: youtube as a site of counternarratives to transnormativity. (Doctoral thesis). Institute for Women's, Gender and Sexuality Studies, Georgia State University, Georgia, United States of America. https://scholarworks.gsu.edu/cgi/viewconten t.cgi?article $=1063 \&$ context=wsi_theses

Oliveira, A. L. G. (2013). Os homens transexuais brasileiros e o discurso pela (des)patologização da transexualidade. In: Anais do Seminário Internacional Fazendo Gênero 10, Florianópolis, Santa Catarina, Brasil. http://www.fazendogenero.ufsc.br/10/resources/anais/20/138 4804329_ARQUIVO_AndreLucasGuerreiroOliveira.pdf. 
Research, Society and Development, v. 10, n. 11, e45101119090, 2021

(CC BY 4.0) | ISSN 2525-3409 | DOI: http://dx.doi.org/10.33448/rsd-v10i11.19090

Pelúcio, L. (2005). "Toda quebrada na plástica" - Corporalidade e construção de gênero entre travestis paulistas. Campos - Revista de Antropologia, 6, 97112. http://dx.doi.org/10.5380/cam.v6i0.4509

Preciado, P. B. (2011). Multidões queer: notas para uma política dos "anormais". Rev. Est. Fem., 19(1), 11-20. https://doi.org/10.1590/S0104026X2011000100002

Preciado, P. B. (2014). Manifesto contrassexual: práticas subversivas de identidade sexual. n-1 edições.

Rego, F. C. V. S. do. (2015). Viver e esperar viver: corpo e identidade na transição de gênero de homens trans. (Dissertação de mestrado). Centro de Ciências Humanas, Letras e Artes, Universidade Federal do Rio Grande do Norte, Natal, Brasil. https://repositorio.ufrn.br/jspui/bitstrea m/123456789/20730/1/ViverEsperarViver_Rego_2015.pdf

Rocon, P. C., Rodrigues, A. \& Sodré, F. (2016). Regulamentação da vida no processo transexualizador brasileiro: uma análise sobre a política pública. Revista Katál, 19 (2), 260-269. https://doi.org/10.1590/1414-49802016.00200011

Rocon, P. C., et al. (2019). Acesso à saúde pela população trans no Brasil: nas entrelinhas da revisão integrativa. Trab. Educ. Saúde, 18 (1), 1-18. http://dx.doi.org/10.1590/1981-7746-sol00234

Rodrigues, S. G. C. \& Mesquita, C. N. C. (2019). Reflexões sobre a temática da transexualidade no ambiente universitário: um estudo exploratório. In: Anais do Encontro Internacional e Nacional de Política Social, Vitória, Espírito Santo, Brasil. https://periodicos.ufes.br/einps/article/view/25817/17959

Serano, J. (2007). Skirt Chasers Why the Media Depicts the Trans Revolution in Lipstick and Heels, In: Whipping Girl: A Transsexual Woman on Sexism and The Scapegoating of Femininity.

Stoller, R. (1982). A experiência transexual. Imago.

Stryker, S. (2017). Transgender History: the roots of today's revolution. Seal Press.

Tadvick, T. (2018). Practicing gender in online spaces. (Undergraduate honors thesis). Sociology Department, University of Colorado Boulder, Boulder, United States of America. Recuperado de https://scholar.colorado.edu/concern/undergraduate_honors_theses/9z9030273?locale=pt-BR

Vergueiro, V. (2015). Por inflexões decoloniais de corpos e identidades de gênero inconformes: uma análise autoetnográfica da cisgeneridade como normatividade. (Dissertação de Mestrado). Instituto de Humanidades, Artes e Ciências, Universidade Federal da Bahia, Bahia, Brasil. https://www.google.com.br/url?sa=t\&rct=j\&q=\&esrc=s\&source=web\&cd=\&cad=rja\&uact=8\&ved=2ahUKEwjU0vbEl7byAhW1pZUCHTs2Bp8QFnoECAU QAQ\&url=https\%3A\%2F\%2Frepositorio.ufba.br\%2Fri\%2Fhandle\%2Fri\%2F19685\&usg=AOvVaw0iWftQioIHEOwGgcmFjKUc

Zhang, C. M. (2019). Biopolitical and necropolitical constructions of the incarcerated trans body. Columbia Journal of Gender and Law, 37 (2), $257-299$. https://doi.org/10.7916/cjgl.v37i2.2787 